\title{
Effect of conjugated linoleic acid on blood pressure: a meta-analysis of randomized, double-blind placebo-controlled trials
}

\author{
Jing Yang ${ }^{1,2 \dagger}$, Hai-Peng Wang ${ }^{3 \dagger}$, Ling-Mei Zhou' ${ }^{1}$ Li Zhou ${ }^{2}$, Tan Chen ${ }^{3}$ and Li-Qiang Qin ${ }^{* *}$
}

\begin{abstract}
Background: Numerous studies on animals evidenced that conjugated linoleic acid (CLA) could decrease blood pressure (BP) in several rat models. However, such beneficial effect is not completely supported by studies on humans.

Methods: We searched the Pubmed, Cochrane Library, and the ClinicalTrials.gov databases for relevant randomized, double-blind placebo-controlled trials up to August 2014 to perform a meta-analysis. A random-effects model was used to calculate the combined treatment effects.

Results: Eight studies with nine trials, which involved 638 participants with CLA supplementation ranging from $2.0 \mathrm{~g} /$ day to $6.8 \mathrm{~g} / \mathrm{day}$, were included in this meta-analysis. Compared with placebo, the pooled estimate of change was $-0.03 \mathrm{~mm} \mathrm{Hg}(95 \% \mathrm{Cl}:-2.29,2.24, \mathrm{P}=0.98)$ and $0.69 \mathrm{~mm} \mathrm{Hg}(95 \% \mathrm{Cl}:-1.41,2.80, \mathrm{P}=0.52)$ in systolic and diastolic BPs, respectively. No significant heterogeneity across studies for systolic BP; however, substantial heterogeneity for diastolic BP was identified. Publication bias was not found for both systolic and diastolic BPs.

Conclusion: The findings of this meta-analysis did not support the overall favorable effect of CLA supplementation on BP regulation.
\end{abstract}

Keywords: Conjugated linoleic acid, Dairy products, Blood pressure, Meta-analysis

\section{Introduction}

Conjugated linoleic acid (CLA) is a mixture of positional and geometric isomers of linoleic acid, an 18-carbon polyunsaturated fatty acid. CLA isomers are naturally occurring fatty acids identified in ruminant animals. The most commonly studied CLA isomers are the cis (c)9, trans $(\mathrm{t}) 11$ and the $\mathrm{t} 10, \mathrm{c} 12-\mathrm{CLA}$ isomers [1]. In general, commercial CLA supplements usually equally contain these two active isomers, whereas, CLA in dairy products consists over $90 \%$ of c9, t11-CLA isomer [2].

Trans fatty acid may adversely influence human health; yet, evidence has shown that CLA exerts many beneficial effects, such as anti-obesity, anti-diabetic and antiinflammatory properties [3]. Of note, CLA was also

\footnotetext{
* Correspondence: qinliqiang@suda.edu.cn

${ }^{\dagger}$ Equal contributors

'Department of Nutrition and Food Hygiene, School of Public Health, Soochow University, 199 Renai Road, Dushu Lake Higher Education Town, Suzhou 215123, China

Full list of author information is available at the end of the article
}

found to lower blood pressure (BP) among various rat models [4-8]. A possible mechanism by which CLA might influence BP could be through endothelial function, NO production and eicosanoids production $[8,9]$. In this regard, CLA may also influence BP of humans. Several human studies demonstrated that CLA supplementation can lower BP [10-13]; however, others showed no significant BP-lowering effect [14-21]. These inconsistent findings may result from variation in sample size, study population, or study quality. Thus, the present study aimed to systematically examine the effect of CLA supplementation on BP by conducting a meta-analysis of randomized controlled trials (RCTs) designed by doubleblind and placebo.

\section{Materials and methods \\ Search strategy \\ We followed the Preferred Reporting Items for System- atic Reviews and Meta-analysis (PRISMA) guidelines in}


the report of this meta-analysis [22]. We searched Pubmed, Cochrane library and the ClinicalTrials.gov databases through August 2014 for relevant studies, using terms of "conjugated linoleic acid" or "CLA" in combination with "blood pressure" or "hypertension". No restriction was imposed. In addition, we carried out a manual search using reference lists of original articles and recent reviews.

\section{Study selection}

Studies were included if they 1) were randomized, double-blind placebo-controlled trials in adults (Age $\geq$ 18 years old); 2) CLA was the only active intervention in treatment group; 3 ) had intervention duration $\geq 4$ weeks; 4) had a control or a comparison group; 5) included the net changes of systolic and/or diastolic blood pressure (SBP/DBP) and their corresponding standard deviation (SD) or available data to calculate these values.

\section{Data extraction}

The data were extracted independently by two researchers in duplicate (J Yang, HP Wang) according to the described selection criteria using an electronic form. Disagreement was resolved by discussion with the third research (LQ Qin). The following data were extracted from study: first author's name, publication year, study design, intervention method, study period, sample size, daily dose of CLA (c9, t11 and t10, c12 isomers). We also extracted the following participant characteristics: gender, mean age, body mass index (BMI), baseline SBP/ DBP and their changes of each study. Study quality was assessed by a modified Jadad Scale [23], where total score ranges 0 to 7 points based on their description of randomization, concealment of allocation, double blinding, withdrawn or drop-outs explanation.

\section{Statistical methods}

The net changes were calculated as the difference between the baseline and final values of BP. If only SD for the baseline and final values were provided, SD for the net changes were imputed according to the method of Follmann using a correlation coefficient of 0.5 [24]. Overall effect size was expressed as weighted mean difference (WMD) with 95\% confidence interval (CI) using Stata11 (StataCorp, College Station, TX, USA). The heterogeneity between the studies was tested using the Q test at the $\mathrm{P}<0.10$ level of significance and quantified by the $I^{2}$ statistic, which describes the inconsistency across studies [25]. In general, the random-effects model was used in the presence of significant heterogeneity. In fact, heterogeneity always exists in varying degrees. Thus, results from random effects model, which would be more conservative (and hence more appropriate), were presented in our meta-analysis. We did not conduct subgroup analysis because of the small number of trials. Rather, we performed a sensitivity analysis, in which a single trial was omitted each time and the effect size was recalculated to investigate its influence on the overall effect size. Furthermore, we conducted meta-regression analysis to explore possible sources of heterogeneity across studies. To minimize the likelihood of falsepositive results, we carefully selected a few covariates, including CLA dose, intervention duration and baseline BP. Potential publication bias was assessed using the Begg's funnel plots and Egger's regression test [26]. A $\mathrm{P}<0.05$ was considered statistically significant, except where otherwise specified.

\section{Results}

\section{Search results}

A flow chart of literature search and study selection is presented in Figure 1. A total of 79 potential relevant articles and 14 trials were retrieved for further assessment. Six of these studies, however, were excluded from the analysis because four of them $[11,13,27,28]$ incorporated CLA as part of the active components in treatment group, one adopted an RCT with no double-blind design [19], and the other one used a cross-over RCT design with short intervention duration (3 weeks) [20]. Meanwhile, one study separately determined BP in overweight and obese subjects and was considered as two trials [16]. Finally, eight studies with nine trials were included in this meta-analysis $[10,12,14-18,21]$.

\section{Study characteristics}

The characteristics of the included studies are presents in Table 1. These studies were published from 2000 to 2013, in which five were conducted in Europe, two in Iran, and one in Japan. Sample sizes varied from 38 to 346 with a sum of 318 in the CLA groups and 320 in the control groups. In five studies, both men and women

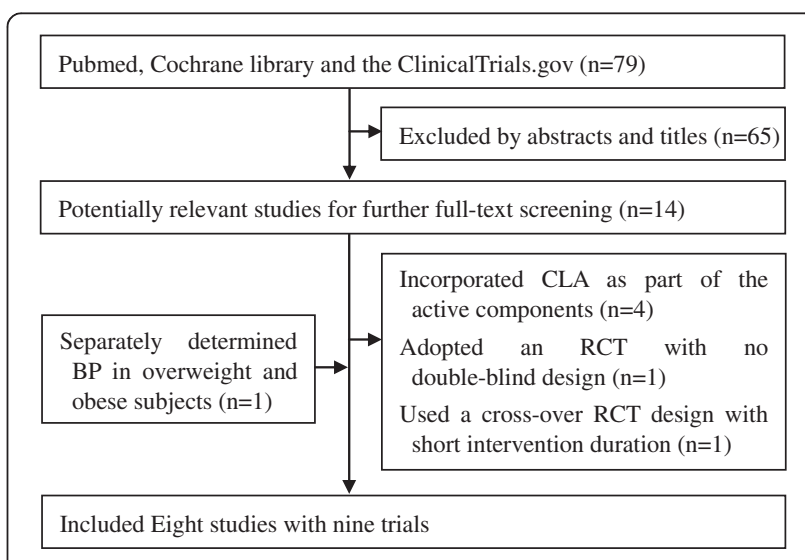

Figure 1 Flow chart of study selection. 
Table 1 Characteristic of the trials and participants in this meta-analysis

\begin{tabular}{|c|c|c|c|c|c|c|c|c|c|c|}
\hline Study & Country & $\begin{array}{l}\text { No. of CLA/ } \\
\text { Control }\end{array}$ & $\begin{array}{l}\text { Age } \\
\text { (Year) }\end{array}$ & $\begin{array}{l}\text { Male } \\
(\%)\end{array}$ & BMI (kg/m2) & $\begin{array}{l}\text { Baseline SBP/DBP } \\
(\mathrm{mm} \mathrm{Hg})\end{array}$ & $\begin{array}{l}\text { CLA amount } \\
(\mathrm{g} / \text { day })^{c}\end{array}$ & Placebo & $\begin{array}{l}\text { Duration } \\
\text { (Weeks) }\end{array}$ & $\begin{array}{l}\text { Jadad } \\
\text { scores }\end{array}$ \\
\hline Berven 2000 & Norway & $25 / 22$ & 47.1 & 63.8 & 29.7 & $139.7 / 85.7$ & $2.65(1.33)$ & olive oil & 12 & 5 \\
\hline Raff 2006 & Denmark & $18 / 20$ & 25.9 & 100 & 22.3 & $119.5 / 61.6$ & $4.7(2.35)$ & Control diet & 5 & 4 \\
\hline Taylor 2006 & UK & $21 / 19$ & 46 & 100 & 33.0 & $124.9 / 82.4$ & $3.2(1.62)$ & olive oil & 12 & 6 \\
\hline Iwata 2007 & Japan & $20 / 20$ & 41.5 & 100 & 28.0 & $127.5 / 77.1$ & $6.8(3.4)$ & safflower oil & 12 & 6 \\
\hline Laso 2007 & Spain & $10 / 11^{a} 10 / 13^{b}$ & 53.9 & 75.0 & $27.6^{a} 33.1^{b}$ & $145.5 / 82.5^{a} 148.5 / 86.0^{b}$ & $3(1.5)$ & Skimmed milk & 12 & 4 \\
\hline Aryaeian 2008 & Iran & $22 / 22$ & 47.1 & 13.6 & 27.8 & 119.8/73.5 & $2(1)$ & oleic sunflower & 12 & 5 \\
\hline Sluijs 2010 & Netherland & $173 / 173$ & 58.4 & 48.3 & 27.9 & $127.4 / 76.1$ & $3.1(0.6)$ & palm oil & 24 & 7 \\
\hline Shadman 2013 & Iran & $19 / 20$ & 45.3 & 46.2 & 27.2 & $122.6 / 81.2$ & $3(1.5)$ & Soybean oil & 8 & 4 \\
\hline
\end{tabular}

${ }^{a}$ Overweight participants; ${ }^{b}$ Obese participants; ${ }^{c}$ Amount of $\mathrm{t} 10, \mathrm{c} 12-\mathrm{CLA}$ is presented in parentheses.

were included as participants, whereas the remaining studies included only men. Except for the study of Raff that involved apparently healthy adults [14], the others included overweight and obese adults (BMI $\left.\geq 25 \mathrm{~kg} / \mathrm{m}^{2}\right)$. No study specified the hypertension status of participants, which the majority were normotensive as indicated by mean BP levels at baseline. Two trials were conducted in patients with rheumatoid arthritis and type 2 diabetes mellitus, respectively [17,21]. Dose of CLA varied from $2 \mathrm{~g} /$ day to $6.8 \mathrm{~g} /$ day, with a median of $3 \mathrm{~g} / \mathrm{d}$. All studies supplemented CLA with a mixture of isomers, and 50:50 isomer blends were used except in the study of Sluijs [18]. Only one trial had full Jadad score $(=7)$. Tree trials had relatively low Jadad score $(=4)$. On the other hand, two studies performed intention-to-treat analysis. Intervention duration lasted from 5 weeks to 24 weeks and 5 studies for 12 weeks.

\section{Effect of CLA on BP}

Compared with placebo, CLA supplementation was associated with an average net change ranging from -11.82 to $4.00 \mathrm{~mm} \mathrm{Hg}$ for SBP and from -7.22 to $6.00 \mathrm{~mm} \mathrm{Hg}$ for DBP. SBP and DBP reductions were statistically significant in only one trial [17], whereas the other trial observed a significant DBP increase [14]. The pooled estimate of change in SBP was $-0.03 \mathrm{~mm} \mathrm{Hg}$ (95\% CI: $-2.29,2.24$; $\mathrm{P}=0.98)$, without significant heterogeneity $\left(I^{2}=22.2 \%\right.$, $\mathrm{P}=0.25$ ) (Figure 2). Meanwhile, the pooled estimate of change in DBP was $0.69 \mathrm{~mm} \mathrm{Hg}$ (95\% CI: $-1.41,2.80$; $\mathrm{P}=0.52$ ), with substantial heterogeneity across trials $\left(I^{2}=52.0 \%, \mathrm{P}=0.03\right)$ (Figure 3$)$. Thus, there was no overall effect of CLA supplementation on both SBP and DBP. Such supplementation even elevated DBP without significance. Neither Begg's test nor Egger's test provided evidence of publication bias (all $\mathrm{P}>0.05$ ).

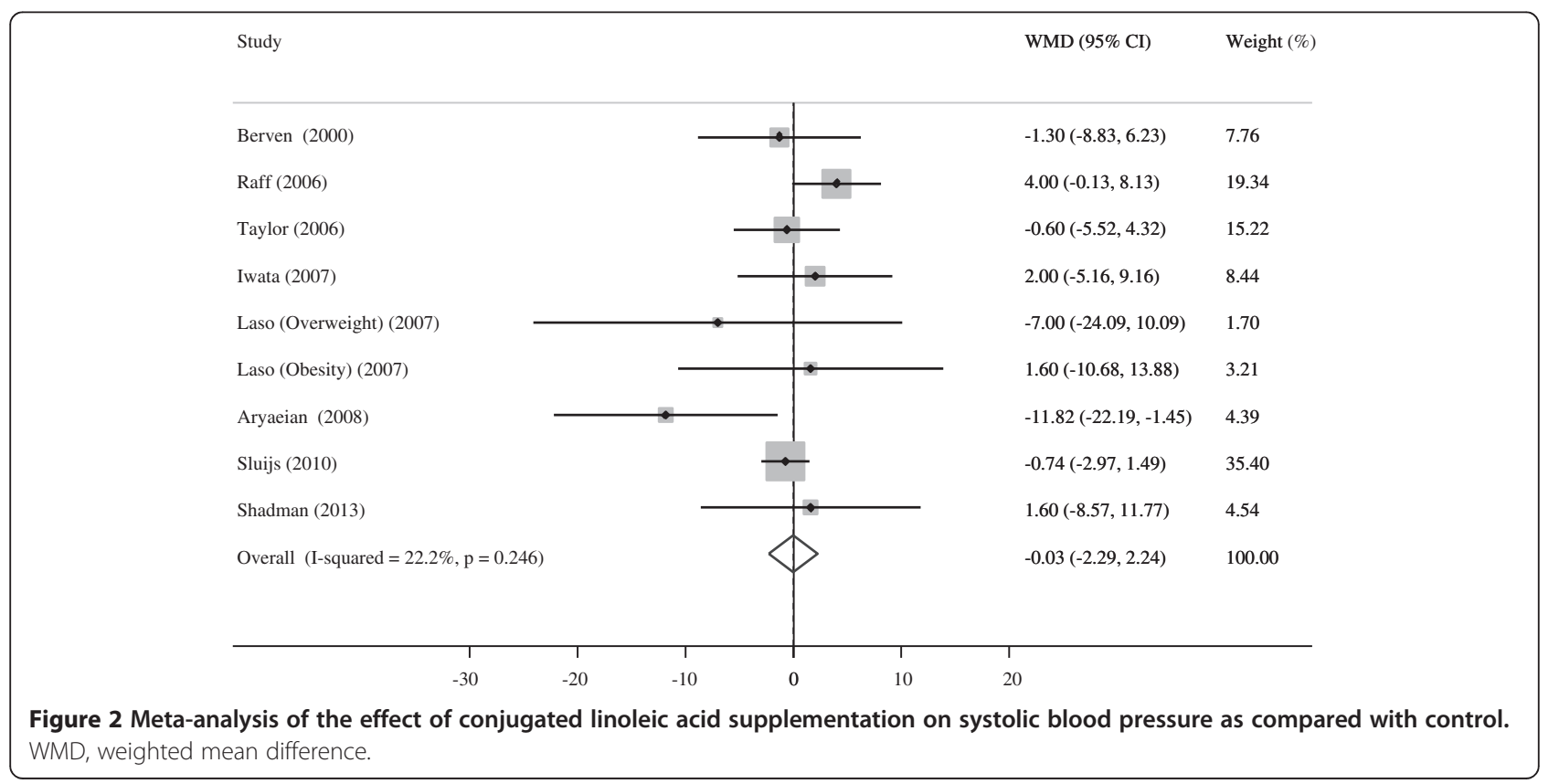




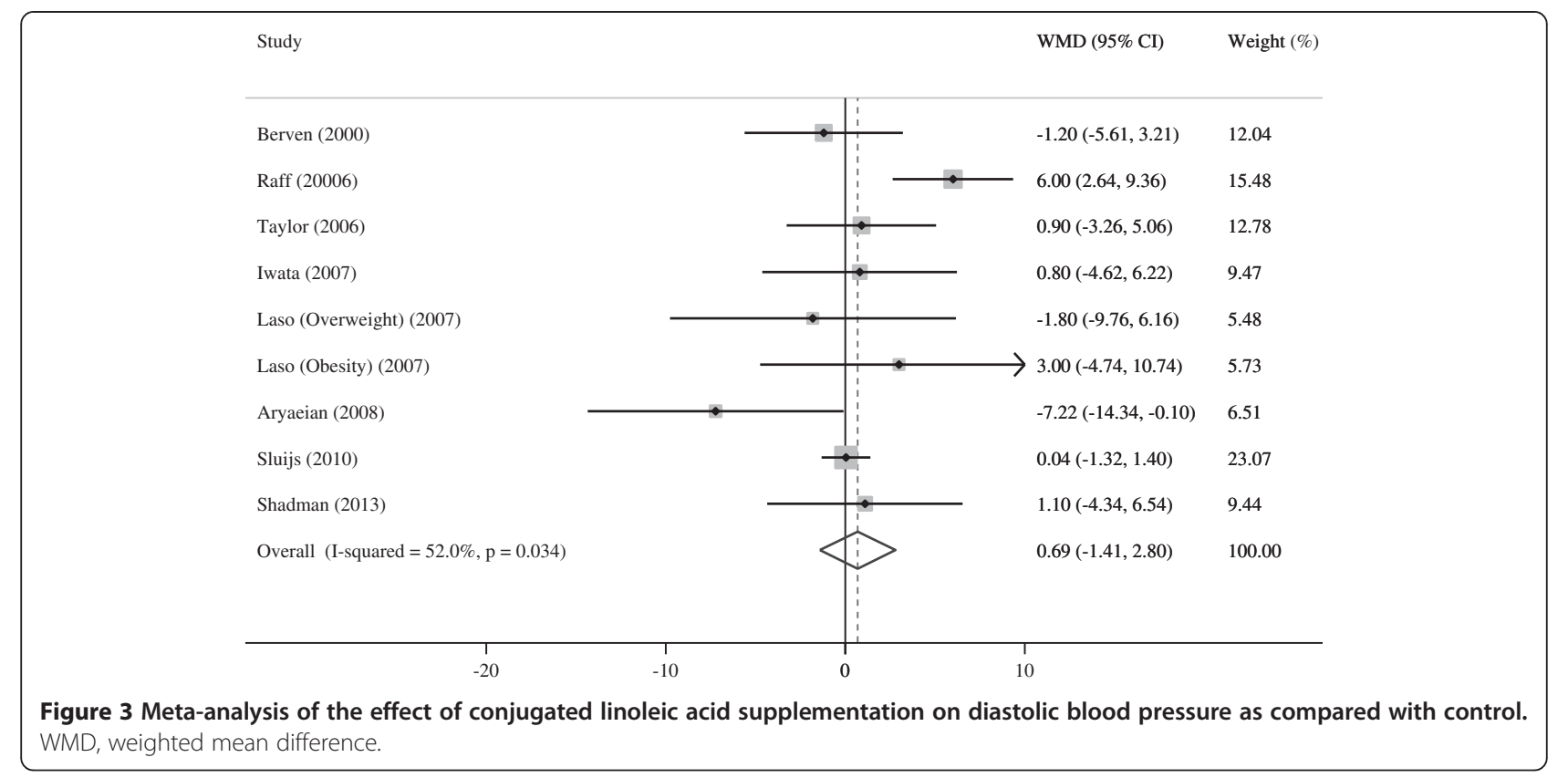

\section{Sensitivity analysis}

Additional analyses examining the influence of an individual trial on the overall effect size by omitting one trial in each turn yielded a range from $0.22 \mathrm{~mm} \mathrm{Hg}$ (95\% CI: $-1.45,1.90)$ to-0.27 mm Hg (95\% CI:-2.83, 2.29) and from $0.92 \mathrm{~mm} \mathrm{Hg}$ (95\% CI:-1.45, 3.28) to$0.06 \mathrm{~mm} \mathrm{Hg}$ (95\% CI:-1.20, 1.08) for SBP and DBP, respectively. None of the individual studies appeared to have appreciable impacts on the overall combined effect sizes.

\section{Meta-regression analyses}

Meta-regression analysis was subsequently conducted to assess whether BP change is related to CLA dose, intervention duration, or baseline BP levels. The results of the analysis revealed that none of these covariates had significant influences on the overall effect sizes (Table 2). However, a trend toward greater reductions in SBP among subjects with higher CLA dose $(\mathrm{r}=-1.78, \mathrm{P}=0.07)$ was observed.

\section{Discussion}

Hypertension significantly contributes to the morbidity and mortality associated with cardiovascular disease. In this event, hypertension must necessarily be prevented. Nevertheless, this meta-analysis of randomized, doubleblind, placebo-controlled trials found that supplemental CLA does not affect human BP regulation.

In particular, the results of this analysis contradict those of the animal studies, which consistently reported the BP lowering effects of CLA [4-8]. Such discrepancy between human and animal studies may because of the characteristics of observational subjects as animal models already have established hypertension. In the studies including in this meta-analysis, most participants were generally normotensive, in which further decreasing BP was not probable. To surprise, the study of Laso with a relatively higher $\mathrm{BP}(\mathrm{SBP}>130 \mathrm{mmHg}$ or $\mathrm{DBP}>$ $85 \mathrm{mmHg}$ ) also did not observe BP change for supplementation with $3 \mathrm{~g}$ of CLA for 12 weeks [16]. Two human trials reported BP lowering effects of CLA. Herrera discovered that CLA combined with calcium could reduce pregnancy-induced hypertension [11]. Zhao identified that CLA supplementation could enhance the antihypertensive effects of Ramipril among stage 1 hypertension patients [13]. The participants in these two studies were hypertensive, further suggesting the importance of baseline BP for CLA effect. These two studies were excluded in the current meta-analysis because they did not satisfy the selection criteria.

Obesity is a major factor that promotes hypertension. Participants were mostly overweight or obese adults in this meta-analysis. An animal study demonstrated that CLA could reduce the number of large adipocytes, thereby contributing to obesity-related hypertension [7]. In study of Laso, the participants were divided into two groups according to their BMI. Surprisingly, CLA

Table 2 Characteristics associated with net change in blood pressure: univariate meta-analysis analysis

\begin{tabular}{|c|c|c|c|c|}
\hline & \multicolumn{2}{|l|}{ Systolic BP } & \multicolumn{2}{|l|}{ Diastolic BP } \\
\hline & Coefficient $(95 \% \mathrm{Cl})$ & $P$ & Coefficient $(95 \% \mathrm{Cl})$ & $P$ \\
\hline Baseline BP & $-0.11(-0.53,0.30)$ & 0.54 & $-0.23(-0.61,0.14)$ & 0.13 \\
\hline Dose & $-1.78(-3.76,0.20)$ & 0.07 & $-1.32(-3.20,0.56)$ & 0.14 \\
\hline Duration & $-0.16(-0.53,0.20)$ & 0.32 & $-0.19(-0.61,0.23)$ & 0.32 \\
\hline
\end{tabular}


supplementation significantly decreased fat mass in overweight participants, but not in obese [16]. As described above, no change of BP was observed in this population. In fact, elevated BP after CLA supplementation was observed in the study of Raff, where the participants had relatively low BMI [14].

CLA dose is another relevant factor of BP regulation. Meta-regression analyses found a trend toward greater reduction in SBP among participants with higher CLA dose. In most animal experiments, the daily intake of 0.55 to $1 \%$ of CLA is attributed to nearly all of the beneficial effects of CLA [29]. Plasma CLA concentration can reach $200 \mathrm{mM}$ in the rodent animals followed by dietary intakes of $0.5 \%$ CLA [30]. If plasma CLA concentration was taken as a reference parameter, the daily intake of $3.2 \mathrm{~g}$ of CLA in humans must attain the comparable level [31]. Most of the studies in this meta-analysis reached this particular CLA dose. Hence, beneficial effect was expected to be observed in humans. Contrarily, no BP lowering effect was identified in these studies. Thus, apart from CLA dose, different mixture of isomers must also be considered. Divergent effects of $c 9, \mathrm{t} 11$ and $\mathrm{t} 10, \mathrm{c} 12$ isomers on BP were observed in animal studies when these two isomers were separately used $[4,7]$. Interestingly, $\mathrm{t} 10, \mathrm{c} 12$, not $\mathrm{c} 9$, $\mathrm{t} 11$ isomer, significantly suppressed the development of hypertension [4]. The different effects of $\mathrm{c} 9, \mathrm{t} 11$ and $\mathrm{t} 10, \mathrm{c} 12$ isomers were also reported on blood lipid and insulin resistance in human research [32,33]. However, this meta-analysis did not involve human studies that observed the separated isomer of CLA on BP. In study of Iwata, the contents of t10, $\mathrm{c} 12$ and $\mathrm{c} 9, \mathrm{t} 11$ isomers were both $3.4 \mathrm{~g}$, which was the highest measure among all studies. Although BP was significantly deceased at 12 weeks than at the baseline, BP was simultaneously decreased in the control group, resulting in no beneficial effect of CLA [12].

Several limitations of this meta-analysis must be acknowledged. First, only nine randomized trials were included; thus, subgroup analyses were planned, but not performed. Such analyses stratified by location, intervention duration, or study design might be informative, yet they would have increased the risk of type I errors. Second, most studies included in this meta-analysis were not primarily designed to investigate the CLA effect on $\mathrm{BP}$. Thus, factors related with BP were maybe vague, such as intentional lifestyle or behavioral change, method to measure BP. Third, food intake was not controlled in several studies, and the participants may possibly consumed extra CLA from diet source. However, the daily intake of CLA in ruminant products was estimated 152 and $212 \mathrm{mg}$ in women and men, respectively [34]. Theses measures can be neglected in relatively higher CLA supplementation. Finally, substantial heterogeneity across trials in DBP was determined. In this meta-analysis, random effects model was used to estimate the overall effect size.

Our study had some strengths. Because individual studies had insufficient statistical power, our metaanalysis enhanced the power to detect a possible association and provided more reliable estimates. All included studies were randomized, double-blind, placebocontrolled trials, which minimized biases and suggested a high internal validity. In addition, results of sensitivity analyses supported the robustness of the findings. Finally, publication bias, the selective reporting of studies featuring positive or extreme results, may result in overestimation of relationship between CLA and BP. However, no publication bias was found in this meta-analysis.

On the basis of the current evidence, the findings of this work do not support the overall favorable effect of CLA supplementation on BP regulation. Whether the effects of CLA on BP are related to baseline BP, obese status, and intervention dose or duration is yet to be determined. Further studies must be accumulated for subgroup analysis according to the above characteristics and study design.

\section{Competing interests}

The authors declare that they have no competing interests.

\section{Authors' contributions}

LQQ contributed to the design of the study. JY, HPW and LQQ performed the data analysis and prepared the manuscript. LMZ helped with the data analysis, LZ and DC helped with article review. All authors read and approved the final manuscript.

\section{Acknowledgments}

This work was supported by grants from the National Natural Science Foundation of China (No. 81472974, 81273067), the Soochow scholar project from Soochow University to Li-Qiang Qin and the Priority Academic Program Development (PAPD).

\section{Author details}

${ }^{1}$ Department of Nutrition and Food Hygiene, School of Public Health, Soochow University, 199 Renai Road, Dushu Lake Higher Education Town, Suzhou 215123, China. ${ }^{2}$ Department of Clinical Nutrition, The First Affiliated Hospital of Soochow University, 188 Shizi Street, Suzhou 215006, China. ${ }^{3}$ Department of Cardiology, The First Affiliated Hospital of Soochow University, 188 Shizi Street, Suzhou 215006, China.

Received: 29 September 2014 Accepted: 7 February 2015 Published online: 18 February 2015

\section{References}

1. Pariza MW, Park Y, Cook ME. The biologically active isomers of conjugated linoleic acid. Prog Lipid Res. 2001;40(4):283-98.

2. Lock AL, Bauman DE. Modifying milk fat composition of dairy cows to enhance fatty acids beneficial to human health. Lipids. 2004;39(12):1197-206.

3. Dilzer A, Park Y. Implication of conjugated linoleic acid (CLA) in human health. Crit Rev Food Sci Nutr. 2012;52(6):488-513.

4. Nagao K, Inoue N, Wang YM, Hirata J, Shimada Y, Nagao T. The 10trans,12cis isomer of conjugated linoleic acid suppresses the development of hypertension in Otsuka Long-Evans Tokushima fatty rats. Biochem Biophys Res Commun. 2003;306(1):134-8.

5. Nagao K, Inoue N, Wang YM, Yanagita T. Conjugated linoleic acid enhances plasma adiponectin level and alleviates hyperinsulinemia and hypertension in Zucker diabetic fatty $(\mathrm{fa} / \mathrm{fa})$ rats. Biochem Biophys Res Commun. 2003;310(2):562-6. 
6. Inoue N, Nagao K, Hirata J, Wang YM, Yanagita T. Conjugated linoleic acid prevents the development of essential hypertension in spontaneously hypertensive rats. Biochem Biophys Res Commun. 2004;323(2):679-84.

7. DeClercq V, Taylor CG, Zahradka P. Isomer-specific effects of conjugated linoleic acid on blood pressure, adipocyte size and function. Br J Nutr. 2012;107(10):1413-21.

8. DeClercq V, Taylor CG, Wigle J, Wright B, Tworek L, Zahradka P. Conjugated linoleic acid improves blood pressure by increasing adiponectin and endothelial nitric oxide synthase activity. J Nutr Biochem. 2012;23(5):487-93.

9. Yamasaki M, Yanagita T. Adipocyte response to conjugated linoleic acid. Obes Res Clin Pract. 2013;7(4):e235-42.

10. Berven $G$, Bye A, Hals O, Blankson H, Fagertun $H$, Thom E, et al. Safety of conjugated linoleic acid (CLA) in overweight or obese human volunteers. Eur J Lipid Sci Technol. 2000;102:455-62.

11. Herrera JA, Arevalo-Herrera M, Shahabuddin AK, Ersheng G, Herrera S, Garcia $R G$, et al. Calcium and conjugated linoleic acid reduces pregnancy-induced hypertension and decreases intracellular calcium in lymphocytes. Am J Hypertens. 2006;19(4):381-7.

12. Iwata T, Kamegai T, Yamauchi-Sato Y, Ogawa A, Kasai M, Aoyama T, et al. Safety of dietary conjugated linoleic acid (CLA) in a 12-weeks trial in healthy overweight Japanese male volunteers. J Oleo Sci. 2007;56(10):517-25.

13. Zhao WS, Zhai JJ, Wang YH, Xie PS, Yin XJ, Li LX, et al. Conjugated linoleic acid supplementation enhances antihypertensive effect of ramipril in Chinese patients with obesity-related hypertension. Am J Hypertens. 2009;22(6):680-6.

14. Raff M, Tholstrup T, Sejrsen K, Straarup EM, Wiinberg N. Diets rich in conjugated linoleic acid and vaccenic acid have no effect on blood pressure and isobaric arterial elasticity in healthy young men. J Nutr. 2006:136(4):992-7.

15. Taylor JS, Williams SR, Rhys R, James P, Frenneaux MP. Conjugated linoleic acid impairs endothelial function. Arterioscler Thromb Vasc Biol. 2006;26(2):307-12.

16. Laso N, Brugue E, Vidal J, Ros E, Arnaiz JA, Carne X, et al. Effects of milk supplementation with conjugated linoleic acid (isomers cis-9, trans-11 and trans-10, cis-12) on body composition and metabolic syndrome components. Brit J Nutr. 2007:98(4):860-7.

17. Aryaeian N, Shahram F, Djalali M, Eshragian MR, Djazayeri A, Sarrafnejad A, et al. Effect of conjugated linoleic acid, vitamin $E$ and their combination on lipid profiles and blood pressure of Iranian adults with active rheumatoid arthritis. Vasc Health Risk Manag. 2008;4(6):1423-32.

18. Sluijs I, Plantinga Y, de Roos B, Mennen LI, Bots ML. Dietary supplementation with cis-9, trans-11 conjugated linoleic acid and aortic stiffness in overweight and obese adults. Am J Clin Nutr. 2010;91(1):175-83.

19. Carvalho RF, Uehara SK, Rosa G. Microencapsulated conjugated linoleic acid associated with hypocaloric diet reduces body fat in sedentary women with metabolic syndrome. Vasc Health Risk Manag. 2012;8:661-7.

20. Engberink MF, Geleijnse JM, Wanders AJ, Brouwer IA. The effect of conjugated linoleic acid, a natural trans fat from milk and meat, on human blood pressure: results from a randomized crossover feeding study. J Hum Hypertens. 2012;26(2):127-32.

21. Shadman Z, Taleban FA, Saadat N, Hedayati M. Effect of conjugated linoleic acid and vitamin E on glycemic control, body composition, and inflammatory markers in overweight type2 diabetics. J diabetes metab disord. 2013;12(1):42.

22. Moher D, Liberati A, Tetzlaff J, Altman DG. Preferred reporting items for systematic reviews and meta-analyses: the PRISMA statement. Ann Intern Med. 2009;151(4):264-9.

23. Jadad AR, Moore RA, Carroll D, Jenkinson C, Reynolds DJ, Gavaghan DJ, et al. Assessing the quality of reports of randomized clinical trials: is blinding necessary? Control Clin Trials. 1996;17(1):1-12.

24. Follmann D, Elliott $P$, Suh I, Cutler J. Variance imputation for overviews of clinical trials with continuous response. J Clin Epidemiol. 1992;45(7):769-73.

25. Higgins JP, Thompson SG, Deeks JJ, Altman DG. Measuring inconsistency in meta-analyses. BMJ. 2003;327(7414):557-60.

26. Egger M, Davey Smith G, Schneider M, Minder C. Bias in meta-analysis detected by a simple, graphical test. BMJ. 1997;315(7109):629-34.

27. Diaz ML, Watkins BA, Li Y, Anderson RA, Campbell WW. Chromium picolinate and conjugated linoleic acid do not synergistically influence diet- and exercise-induced changes in body composition and health indexes in overweight women. J Nutr Biochem. 2008;19(1):61-8.
28. Ormsbee MJ, Rawal SR, Baur DA, Kinsey AW, Elam ML, Spicer MT, et al. The effects of a multi-ingredient dietary supplement on body composition, adipokines, blood lipids, and metabolic health in overweight and obese men and women: a randomized controlled trial. J Int Soc Sports Nutr. 2014;11:37.

29. Belury MA. Dietary conjugated linoleic acid in health: physiological effects and mechanisms of action. Annu Rev Nutr. 2002;22:505-31.

30. Banni S, Angioni E, Casu V, Melis MP, Carta G, Corongiu FP, et al. Decrease in linoleic acid metabolites as a potential mechanism in cancer risk reduction by conjugated linoleic acid. Carcinogenesis. 1999;20(6):1019-24.

31. Mele MC, Cannelli G, Carta G, Cordeddu L, Melis MP, Murru E, et al. Metabolism of $\mathrm{C} 9$, $\mathrm{t} 11$-conjugated linoleic acid (CLA) in humans. Prostaglandins Leukot Essent Fatty Acids. 2013;89(2-3):115-9.

32. Tricon S, Burdge GC, Kew S, Banerjee T, Russell JJ, Jones EL, et al. Opposing effects of cis-9, trans-11 and trans-10, cis-12 conjugated linoleic acid on blood lipids in healthy humans. Am J Clin Nutr. 2004;80(3):614-20.

33. Appel LJ, Moore TJ, Obarzanek E, Vollmer WM, Svetkey LP, Sacks FM, et al. A clinical trial of the effects of dietary patterns on blood pressure. DASH Collaborative Research Group. N Engl J Med. 1997;336(16):1117-24.

34. Ritzenthaler KL, McGuire MK, Falen R, Shultz TD, Dasgupta N, McGuire MA. Estimation of conjugated linoleic acid intake by written dietary assessment methodologies underestimates actual intake evaluated by food duplicate methodology. J Nutr. 2001;131(5):1548-54.

\section{Submit your next manuscript to BioMed Central and take full advantage of:}

- Convenient online submission

- Thorough peer review

- No space constraints or color figure charges

- Immediate publication on acceptance

- Inclusion in PubMed, CAS, Scopus and Google Scholar

- Research which is freely available for redistribution 